RESEARCH PAPER RP780

Part of Journal of Research of the National Bureau of Standards, Volume 14, April 1935

\title{
RECENT STUDIES OF THE IONOSPHERE ${ }^{1}$
}

\author{
By Samuel S. Kirby and Elbert B. Judson
}

\section{ABSTRACT}

Results of ionosphere measurements utilizing transmissions at vertical incidence and made weekly over a period of 18 months are discussed. Typical graphs of diurnal variations of the E-layer critical frequency and its relation to the ionizing force of the sun are shown for three seasons. Similar graphs for the $\mathrm{F}_{2}$ layer are included as well as a seasonal curve of midday, and maximum critical frequencies of this layer. The absence of midday $\mathrm{F}_{2}$ critical frequencies during the summer is pronounced.

A sporadic E layer appearing at the same virtual height as the normal E, and after the normal $\mathrm{E}$ has reached its critical penetration frequency, is discussed. A comparison of its appearance with local thunderstorms, is tabulated.

The presence of a tentatively named G layer is indicated.

CONTENTS

I. Introduction

II. E layer

III. $\mathrm{F}_{2}$ layer.

IV. Sporadic $\overline{\mathrm{E}}$

VI. Conclusions

\section{INTRODUCTION}

Observations of the virtual heights of the ionosphere, made one day each week and extending over a period from June, 1933 to November 7,1934 have presented an opportunity to continue the study of diurnal and seasonal effects and to compare them generally with other natural phenomena. Furthermore, other new and interesting. phenomena have been observed, wholly due to the continuity of a day's "run" over a large range of frequencies. The purpose of this paper is to present and interpret this series of data.

The method employed in the experiment is essentially that of Breit and Tuve with modifications of technique similar to those described by Kirby, Berkner, and Stuart. ${ }^{2}$

Some data for diurnal variations of $\mathrm{E}$ critical frequencies have been contributed by T. R. Gilliland ${ }^{3}$ of the National Bureau of Standards, from records of ionosphere heights made by his automatic recorder operating over a range of frequencies from 2,500 to $4,400 \mathrm{kc} / \mathrm{s}$. Since these continuous records were available in this band of frequencies, no manual measurements between these limits were necessary.

\footnotetext{
1 Presented in part at the Ninth Annual Convention, Institute of Radio Engineers, Philadelphia, Pa., May 27-30, 1934 .

2 Kirby, Berkner, and Stuart, BS J.Research 12, 15 (1934) RP632; also Proc.Inst.Radio Engrs. 22, 481 (1934).

3 Gilliland, BS J.Research 11, 561 (1933) RP608; also Proc.Inst.Radio Engrs. 22, 236 (1934).
} 
It has been well established that in the latitude of Washington there are two major layers in the ionosphere at all times and a third present in the daytime, especially during the summer. The first two are known as the E layer, 100 to 120 kilometers above the earth, and the $\mathrm{F}_{2}$ layer, at approximately 230 to 350 kilometers virtual height. The third or $\mathrm{F}_{1}$ layer appears at heights of 180 to 240 kilometers. Earlier experiments indicate that radio-frequency energy is returned to earth from these layers by a process of refraction, and these conclusions are further substantiated by the data herein given. The sharp rise in virtual height occurring at the critical penetration frequency and magneto-ionic double refraction which is observed in the $\mathrm{F}_{1}$ and $\mathrm{F}_{2}$ layers, indicate refraction. When magneto-ionic double refraction is observed, the critical frequency occurring at the lower frequency is the ordinary ray while the one at the higher frequency is the extraordinary ray. These phenomena are clearly shown in the graphs in figure 1. Although well-defined critial penetration frequencies are usually found in the $\mathrm{E}$ region, no evidence of magento-ionic double refraction has been observed.

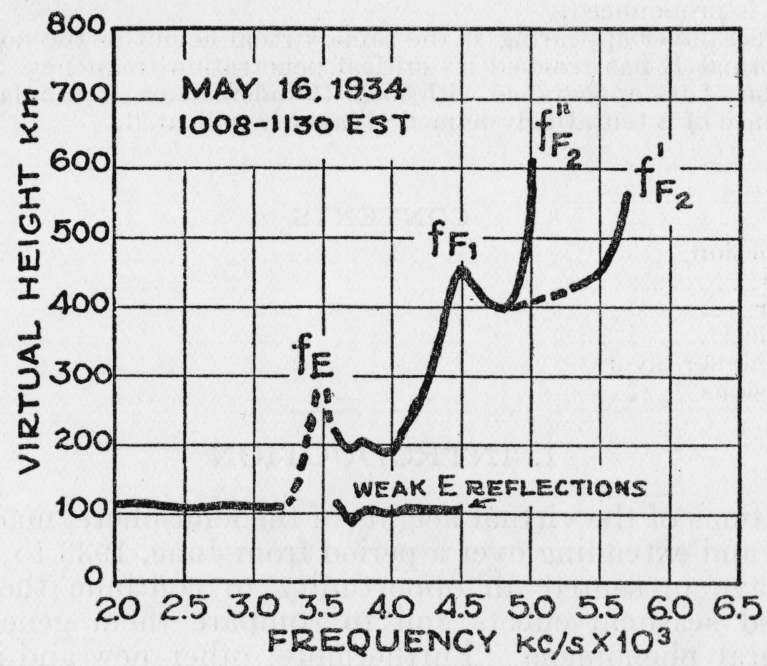

FIGURE 1.-Typical frequency sweep and the three major layers, $\mathrm{E}, \mathrm{F}_{1}$, and $\mathrm{F}_{2}$, with their critical frequencies.

The critical or penetration frequencies are indications of the maximum ionization density of the layers and are defined as the lowest radio frequency of a wave which penetrates a layer at normal incidence.

The relation between the maximum electron density and critical frequency for the ordinary ray in any layer in the absence of dissipation is given by the well-known equation:

where

$$
\begin{aligned}
N & =\frac{f_{c}^{\prime \prime 2} \pi m}{e^{2}} \cdot 10^{6} \\
& =1.24 f_{c}^{\prime \prime 2} \cdot 10^{-2}
\end{aligned}
$$

$N=$ number of ions per cubic centimeter.

$f_{c}^{\prime \prime}=$ critical frequency of ordinary ray in $\mathrm{kc} / \mathrm{s}$,

$m=$ mass of ion in grams,

$e=$ charge on the ion in electrostatic units. 
The relation between the critical frequencies for the ordinary and extraordinary rays is given by the well-known equation:

where

$$
f_{c}^{\prime \prime 2}=f_{c}^{\prime}\left(f_{c}^{\prime}-f_{H}\right)
$$

$f_{c}^{\prime}=$ critical frequency for the extraordinary ray,

$f_{H}=\frac{H e}{2 \pi m c} \times 10^{-3} \mathrm{kc} / \mathrm{s}$

$f_{H} \cong 1,460 \mathrm{kc} / \mathrm{s}$ at Washington for electron ionization.

DIURNAL VARIATION OF CRITICAL FREQUENCY

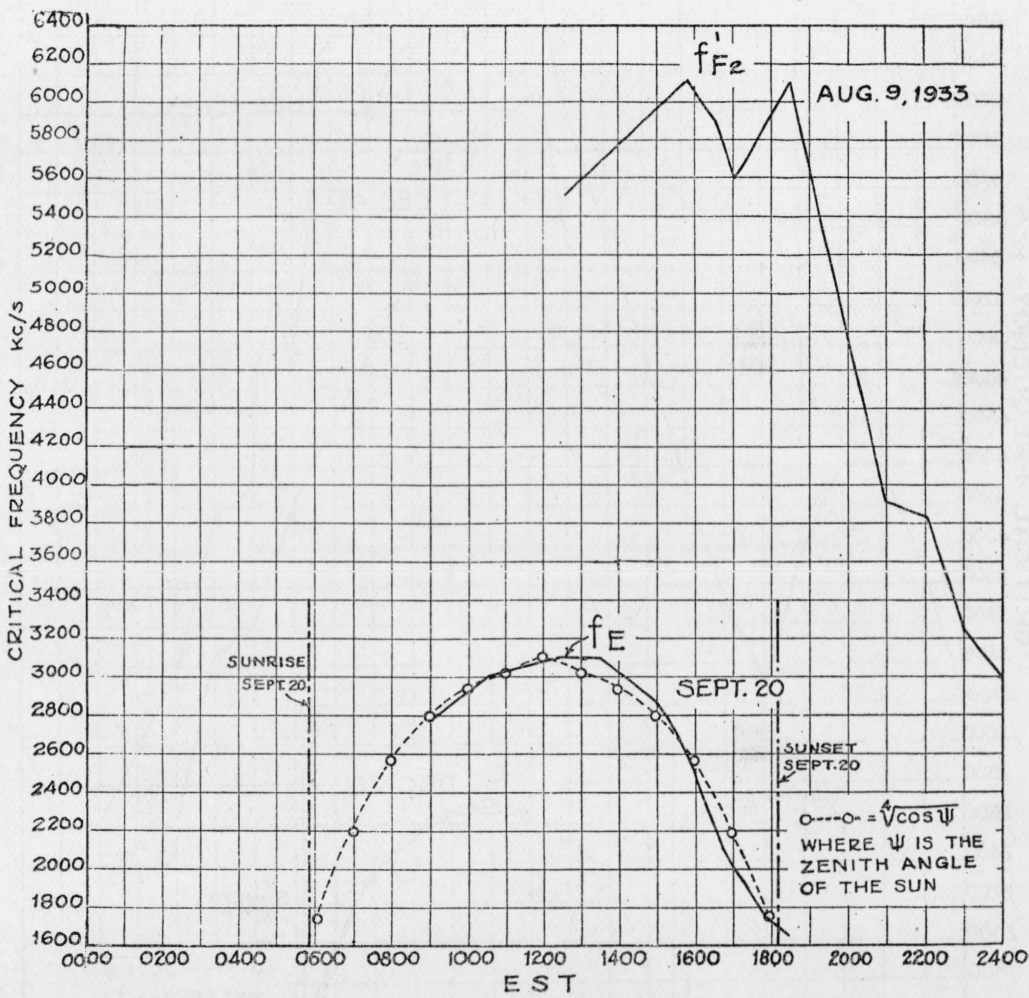

FIgURE 2.-Typical curves of diurnal variation of critical frequencies of $\mathbf{E}$ and $\mathrm{F}_{2}$ layers for fall.

An indication of the diurnal variation of critical frequency for the various layers, corresponding to different seasons of the year, is given in the graphs of figures 2,3 , and 4 .

\section{E LAYER}

E-layer critical-frequency measurements were made at frequencies of $2,500 \mathrm{kc} / \mathrm{s}$ or lower at early and late hours of day, and at night. Data for higher frequencies measured nearer noon were taken from Gilliland's records. The critical frequency of the normal E layer is most clearly in evidence during the fall, winter, and spring. During 
the summer it is frequently obscured by the sporadic $\mathrm{E}$, which will be discussed later. The lower graphs of figures 2, 3, and 4 are for the E layer.

The normal $\mathrm{E}$ critical frequency rises rapidly out of the broadcast band above $1,500 \mathrm{kc} / \mathrm{s}$ shortly after sunrise, comes to a broad maxi-

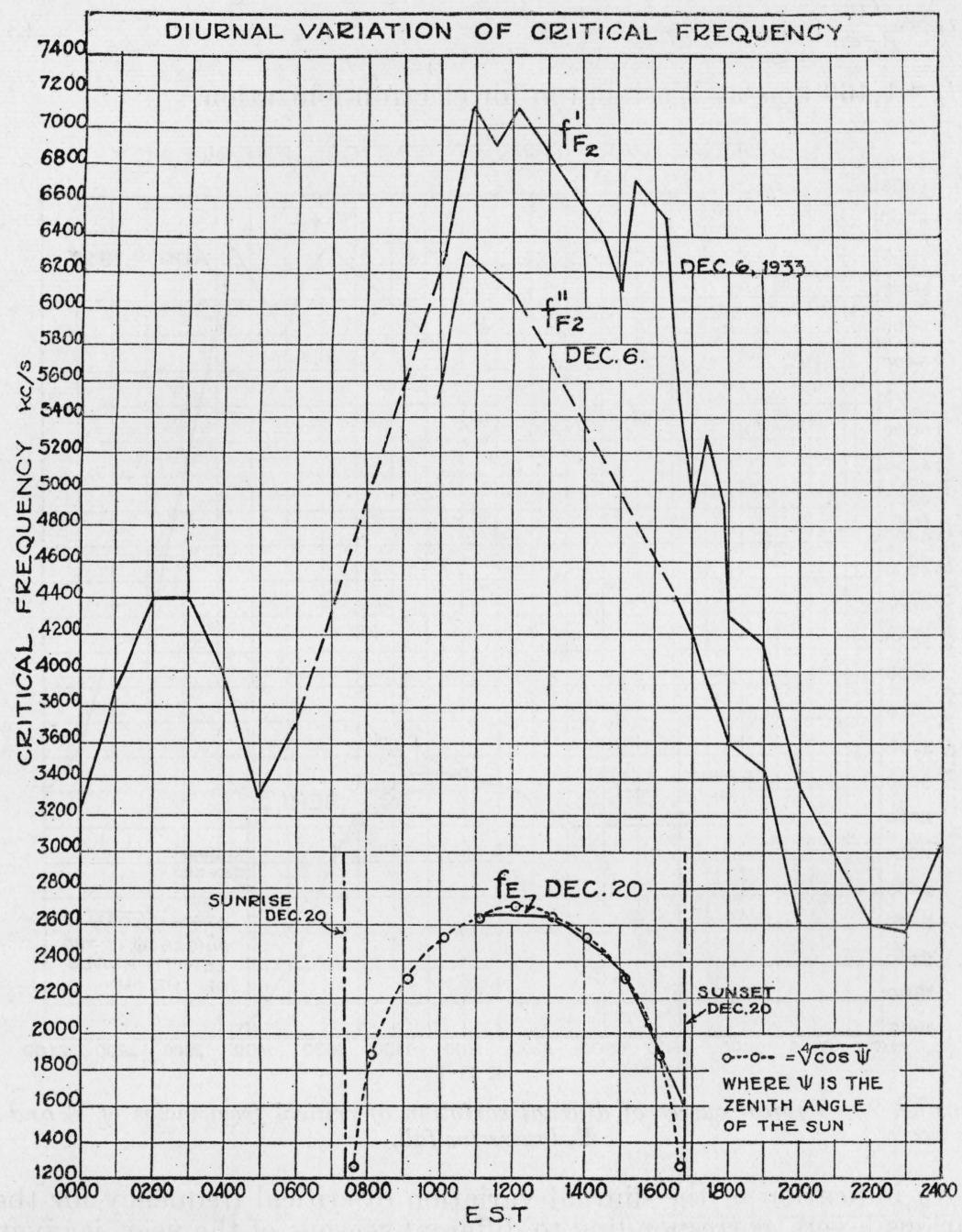

FIgURE 3.-Typical curves of diurnal variation of critical frequencies of $\mathbf{E}$ and $\mathrm{F}_{2}$ layers for winter.

mum at noon, and falls rapidly into the broadcast band just before sunset. The graph of critical frequency versus time of day is approximately symmetrical about the noon axis. These facts indicate a rapid recombination of ions and that the ionization density is a simple function of the ionizing force of the radiation from the sun during most of the time between sunrise and sunset. If recombination is rapid it 
may be shown from results of Pedersen ${ }^{4}$ that the normal diurnal variation of $f_{c}^{\prime \prime}$ should follow the relation of $f_{c}^{\prime \prime}=f_{c}^{\prime \prime} \max (\cos \psi)^{\frac{1}{3}}$, where $\psi$ is the angle which the sun's rays make with the zenith. Data taken during the period preceding and following the eclipse of August 31, 1932 , were found to agree well with this relation. ${ }^{5}$

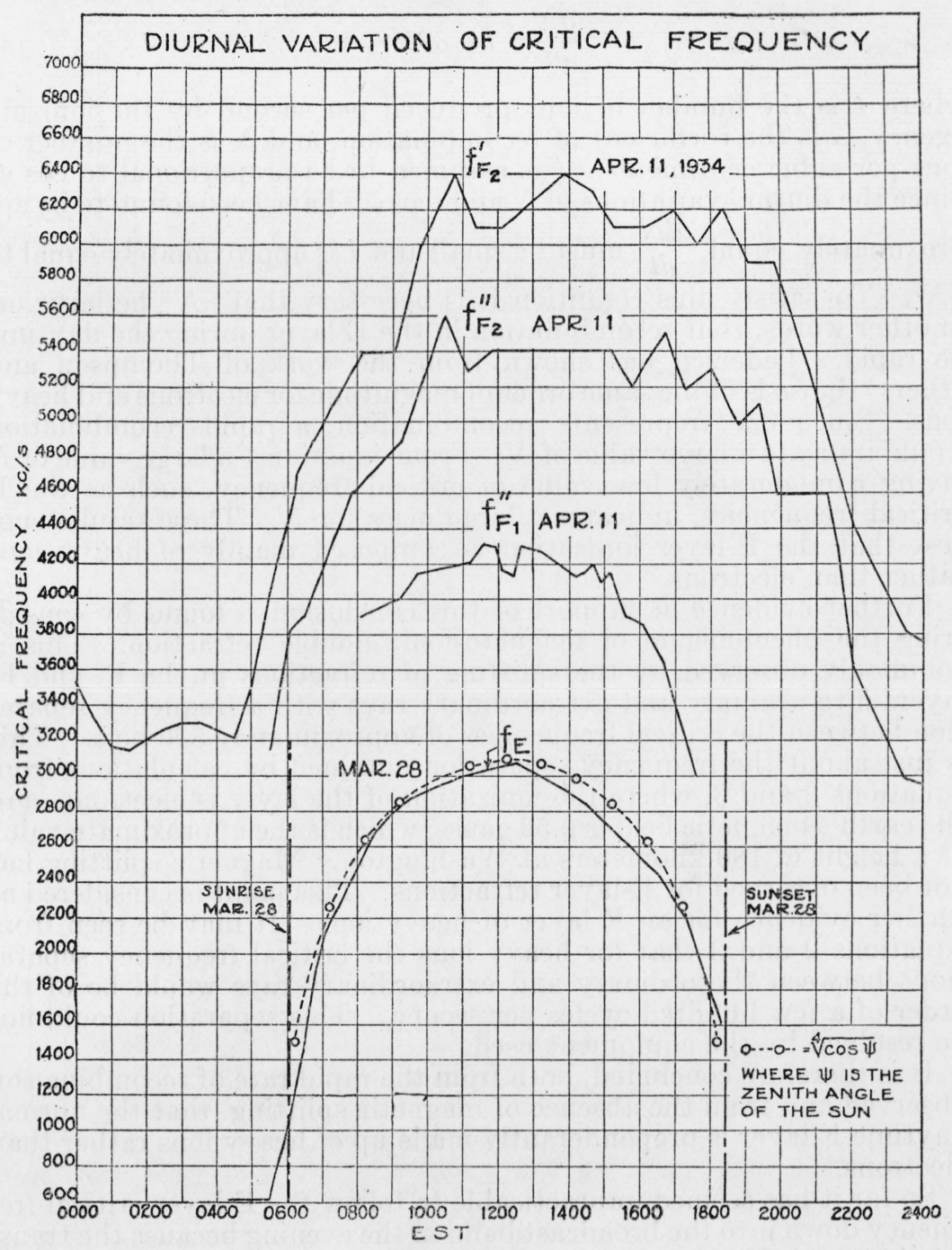

FIgURE 4.-Typical curves of diurnal variation of critical frequencies of $\mathbf{E}$ and $\mathrm{F}_{2}$ layers for spring.

The lower graphs of figures 2, 3, and 4 show the diurnal variation of $f_{\mathrm{E}}$ (critical frequency for the $\mathrm{E}$ layer), determined experimentally and also the diurnal variation of $(\cos \psi)^{\frac{1}{3}}$ plotted in arbitrary units.

\footnotetext{
${ }^{4}$ Pedersen, Propagation of Radio Waves. Chapters V and VI.

8 Kirby, Berkner, Gilliland, and Norton, BS J.Research 11, 829 (1933) RP629; also Proc. Inst. Radio Engrs. 22, 247 (1934).
} 
From these figures it may be seen that the diurnal variations of $f_{E}$ and $(\cos \psi)^{\frac{1}{2}}$ are approximately the same during most of the time that the sun is above the horizon. Also from equation 1 these figures indicate that $N$ is proportional to $(\cos \psi)^{\frac{1}{2}}$ during most of the day.

The rate of change of ionization density may be expressed by

$$
\frac{d N}{d t}=I-\alpha N^{2}
$$

where $I$ is the number of ions produced per second by the ionizing agency, $\alpha$ is the coefficient of recombination, and $N$ is the number of ions per cubic centimeter. $I$ is assumed to be proportional to $\cos \psi$. Since the diurnal variations of $N$ and $(\cos \psi)^{\frac{1}{2}}$ have been found to be approximately equal, $\frac{d N}{d t}$ must be small and $I$ is approximately equal to $\alpha N^{2}$. To satisfy this condition it is necessary that $\alpha N^{2}$ be large or, in other words, that recombination in the E layer during the daytime be rapid. Pedersen has shown from the work of Thompson and others ${ }^{6}$ that $\alpha$ is of the same order of magnitude for electrons and heavy ions. Since $\alpha N^{2}$ represents recombination, a rapid recombination would indicate a large value of $N$. From equation 1 a large value of $N$ giving a moderately low value of critical frequency, such as the $\mathrm{E}$ critical frequencies, indicates a large mass for $N$. These results suggest that the E-layer ionization is composed mainly of heavy ions rather than electrons.

Further evidence in support of this conclusion is found by considering the phenomenon of magneto-ionic double refraction. This is commonly observed by the splitting of refractions in the $\mathrm{F}_{1}$ and $\mathrm{F}_{2}$ layers into ordinary and extraordinary rays with a frequency separation between the critical frequencies of approximately $800 \mathrm{kc} / \mathrm{s}$. This is just about the frequency separation obtained by calculations from equations 2 and 3, where the ionization of the layer is electronic and the earth's magnetic field is 0.52 gauss, which is the approximate value at a height of 180 kilometers at Washington. Magnetic splitting has not been observed for E-layer refractions. This point is considered as further evidence for an $\mathrm{E}$ layer of heavy ions. It may be seen from equations 2 and 3 that for heavy ions the critical frequency separations between the ordinary and extraordinary rays would be of the order of a few hundred cycles per second. This separation could not be resolved by the equipment used.

It is therefore concluded, both from the rapid rate of recombination observed and from the absence of magnetic splitting, that the normal daytime $\mathrm{E}$ layer is preponderantly made up of heavy ions rather than electrons.

So far it has seemed impracticable to follow the E-layer critical frequency down into the broadcast band in the evening because the transmissions would interfere with reception of broadcast programs. Measurements in the band (600 to $1,500 \mathrm{kc} / \mathrm{s})$ made between 2000 EST and sunrise show that the E layer is frequently penetrated at frequencies of 600 to $800 \mathrm{kc} / \mathrm{s}$. No definite $\mathrm{E}$ critical frequency has so far been observed at night. This phenomenon will be discussed under the section on "sporadic E layer."

\footnotetext{
${ }^{8}$ Pedersen, Propagation of Radio Waves. Chapter V.
} 
During the months May to August, E-layer critical frequencies below $2,500 \mathrm{kc} / \mathrm{s}$ during the early and late part of the day, if they existed, were usually obscured by sporadic E-layer reflections. Satisfactory measurements of diurnal variations were not obtained during these months at frequencies below $2,500 \mathrm{kc} / \mathrm{s}$.
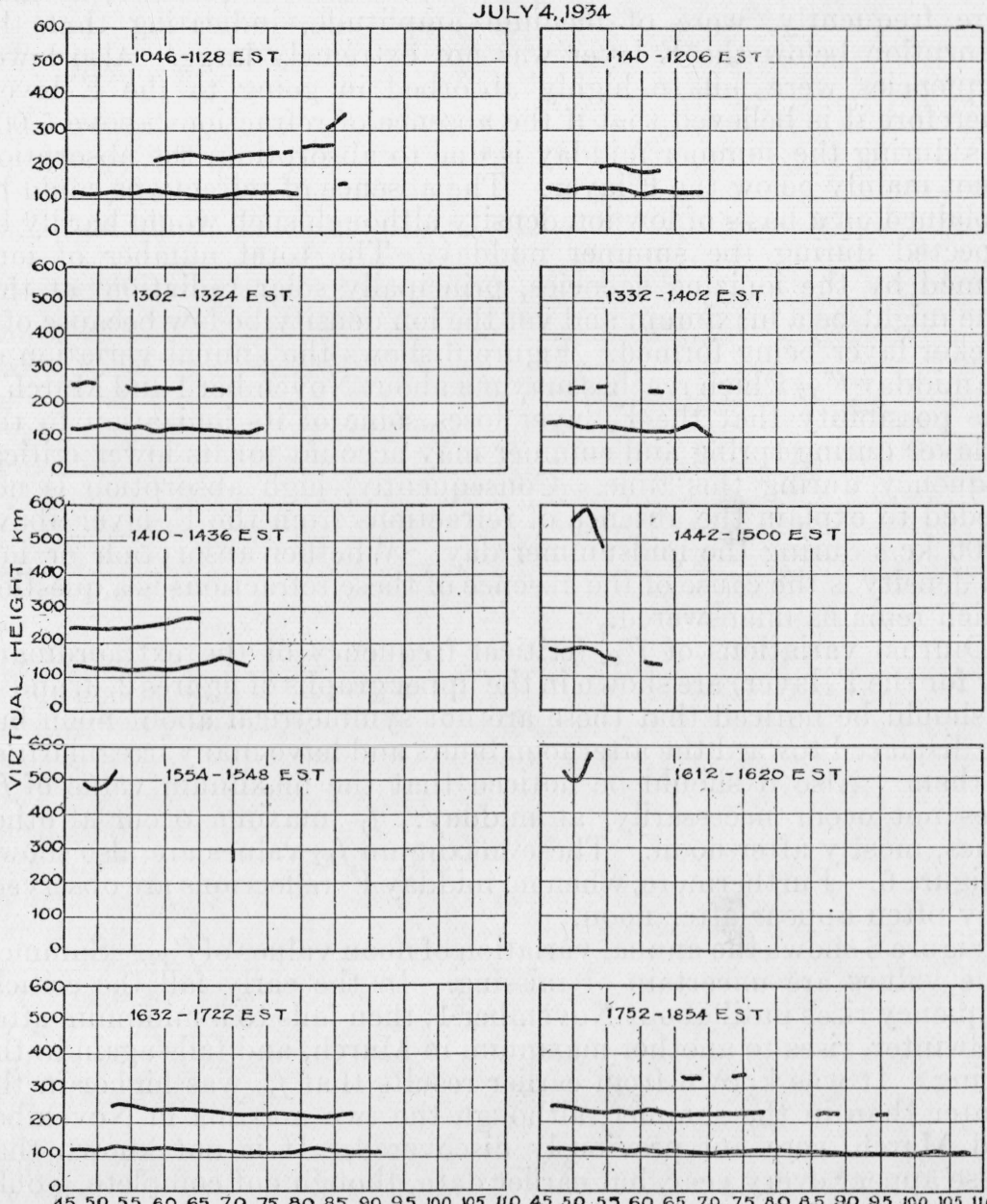

FREQUENCY $\mathrm{kc} / \mathrm{s} \times 10^{3}$

FIGURE 5.-Curve showing the absence of $F_{2}$-layer refractions and the formation of sporadic E-layer reflections, often experienced during the summer.

\section{III. $\mathrm{F}_{2}$ LAYER}

Characteristics of the $\mathrm{F}_{2}$ layer were discussed in an earlier paper. ${ }^{7}$ Some additions to and modifications of the data and conclusions presented there are now desirable.

In general, midsummer, midday measurements of $\mathrm{F}_{2}$-layer heights and critical frequencies were unsatisfactory. Frequently no reflec-

\footnotetext{
7 Kirby, Berkner, and Stuart, BS J. Research 12, 15 (1934) RP632; also Proc. Inst. Radio Engrs. 22, 481 (1934).
} 
tions or refractions could be received at frequencies above $f^{\prime \prime}{ }_{\text {F1 }}$ (critical frequency of the ordinary ray for the $F_{1}$ layer) and sometimes none at lower frequencies. Figure 5 shows a typical summer-day run. The general absence of $\mathrm{F}_{2}$ refractions at frequencies above $5,000 \mathrm{kc} / \mathrm{s}$ may be caused by absorption.

Sporadic E reflections when present at these frequencies, as they were frequently, were of medium amplitude, indicating that the absorption below the $\mathrm{E}$ layer was not extremely large. Also lower frequencies were not so highly absorbed in going to the $\mathrm{E}$ layer. Therefore it is believed that if the absence of refractions above 5,000 $\mathrm{kc} / \mathrm{s}$ during the summer midday is due to absorption, the absorption is not mainly below the $\mathrm{E}$ layer. The absence of refractions could be explained on a basis of low ion density although such would hardly be expected during the summer midday. The total number of ions formed by the ionizing agencies, principally solar radiation, at this time might be a maximum and yet the ion density be low because of a thicker layer being formed. Figure 6 shows the annual variation of the midday $f^{\prime \prime}{ }_{\text {F2 }}$ which reaches maxima about November 1 and March 1. The possibility that the $\mathrm{F}_{2}$ layer loses some of its ionization to the $\mathrm{F}_{1}$ layer during spring and summer may account for its lower critical frequency during this time. Consequently, high absorption is not needed to explain the absence of refractions from the $\mathrm{F}_{2}$ layer above $5,000 \mathrm{kc} / \mathrm{s}$ during the midsummer day. Whether absorption or low ion density is the cause of the absence of these refractions is a question which remains unanswered.

Diurnal variations of $f^{\prime}{ }^{2}$ (critical frequency of the extraordinary ray for the $\mathrm{F}_{2}$ layer) are shown in the upper graphs of figures 2,3 , and 4 . It should be noticed that these are not symmetrical about noon but are displaced toward the afternoon hours and have many irregularities in them. Also it should be noticed that the maximum value of $f_{\mathrm{F} 2}$ does not occur necessarily, at midday. $f_{\mathrm{F} 2}$ maxima occur at other times, mostly after noon. These maximum $f_{\mathrm{F} 2}$ values are also shown in figure 6. Furthermore, when no midday $\mathrm{F}_{2}$ reflections are observed, they often appear after noon.

Figure 6 shows the annual variation of noon values of $f^{\prime}{ }_{\text {F2 }}$. Summertime values are uncertain or missing. In the early fall the critical frequency rises until about November 1 , then falls to a minimum after midwinter, rises to another maximum in March, and falls again in the spring. It was known from earlier results that $f_{\mathrm{F} 2}$ was higher in the winter than in the summer, although the two maxima in November and March were not previously discovered. It is not known that these appear every year, but earlier data, though not complete, would indicate that they probably do.

Experiments indicate that the $\mathrm{F}_{2}$ critical frequency does not follow closely in phase with the ionizing force of the sun, either diurnally or annually. That the sun has a major influence is shown by the diurnal variation from day to night, $f^{\prime}{ }_{F 2}$ rising rapidly after sunrise. The diurnal variations might be explained as a lag due to slow ionization and recombination, but the annual variations can hardly be explained on such a basis. From November to March the variations in the critical frequency of the $\mathrm{F}_{2}$ layer are reasonably consistent with variations of the ionizing force of the sun. 


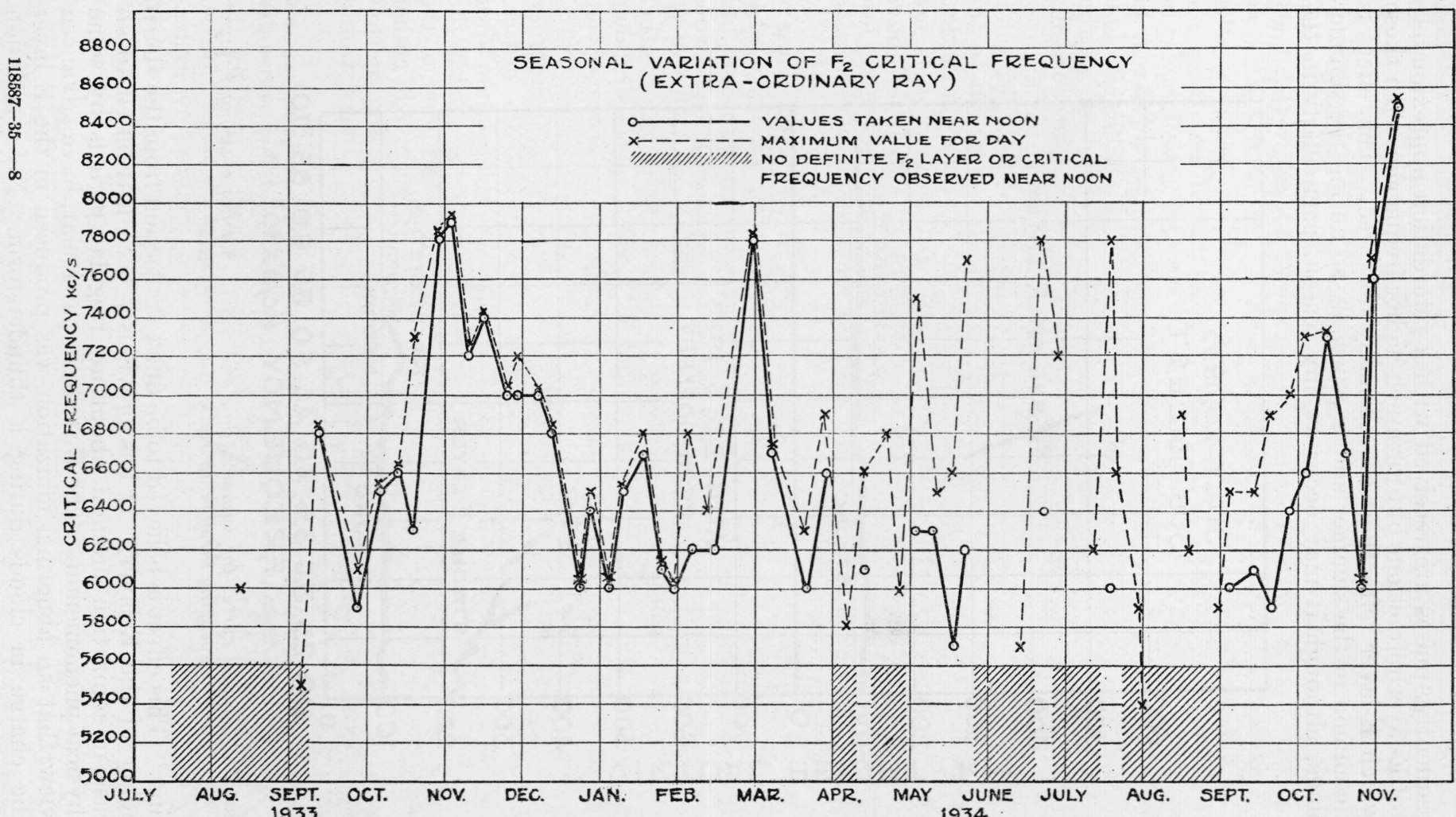

FIGURE 6.-Seasonal variation of the critical frequency of the extraordinary ray for the $F_{2}$ layer at midday, and of the maximum critical frequency obtained for the day. 


\section{SPORADIC E}

Frequently, pulses are received with a retardation approximately that of E-layer refractions but for much higher frequencies than those for which E-layer refractions are normally observed. This effect is very common in the summer and is especially so during the summer evenings, although it may occur at any season, particularly in the

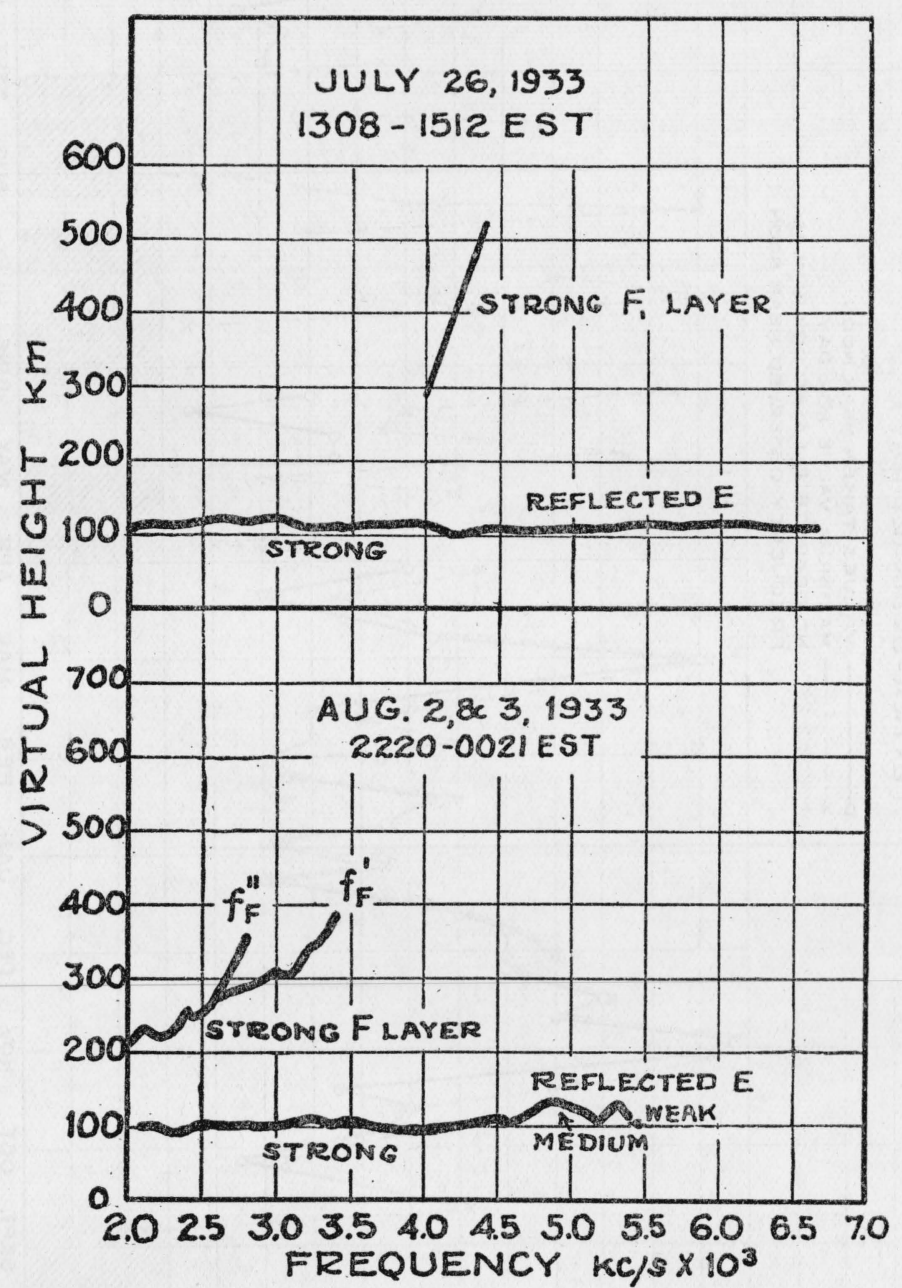

FIgURE 7.-Typical curves for summer, day and night, showing a strong $F$ layer appearing through sporadic E-layer reflections.

evening. This effect is believed to be due to reflection from the sharp boundary of the E layer. It has previously been attributed to an increase in ionization brought about at irregular periods by some geophysical phenomenon. The British, in particular, have advanced the view that an abnormal ionization was produced in the $\mathrm{E}$ layer by the charge in clouds during a thunderstorm. No correlation 
between the occurrence of thunderstorms and sporadic $\mathrm{E}$ reflection has been found at Washington; even local thunderstorms produce no noticeable effect. These reflections have been received at frequencies up to $9,400 \mathrm{kc} / \mathrm{s}$ when the U. S. Weather Bureau reported no thunderstorms within a radius of 300 kilometers during the 24-hour period. So far no correlation between the occurrence of sporadic $\mathrm{E}$ and magnetic storms has been found.

Reasons for believing that the sporadic $\mathrm{E}$ is a reflecting rather than a refracting layer are as follows:

1. The $\mathbf{E}$ layer normally returns energy to some extent at frequencies far above the $\mathrm{E}$ critical frequency. Although these reflections are rather weak and unstable they seem to indicate a more or less sharp boundary.

2. Refractions from the $\mathrm{F}_{1}$ and $\mathrm{F}_{2}$ layers are received simultaneously with sporadic E reflections over frequency bands of several thousand kilocycles per second as is shown in figure 7. Refracting layers are not thus transparent except for frequencies above a critical frequency.

3 . The disappearance of sporadic $\mathrm{E}$ reflections as the frequency is increased is not usually accompanied by a sharp increase in virtual height such as would indicate a critical frequency and such as is shown by the regular refracting layers. The disappearance of the sporadic $\mathrm{E}$ is marked by the gradual weakening of the pulses as the frequency is increased until their amplitude falls below the noise level.

4. Such large increases of E-layer ionization at night do not seem likely when the regular E-layer ionization follows so closely in phase with the ionizing force of the sun during the day. The ionization densities required to refract the waves at these frequencies would be six to eight times normal noon values of ionization density.

Table 1 shows the occurrence of sporadic E reflections during local thunderstorms. On July 4, 28 and August 1, non-local thunderstorms occurred within 100 kilometer radius of Washington. On these days the upper frequency of occurrence of sporadic E (above 4,500 kc/s) was 10,800 , none and $9,200 \mathrm{kc} / \mathrm{s}$ respectively.

TABLE 1.-Sporadic E for days on which local thunderstorms occurred

\begin{tabular}{|c|c|c|c|c|}
\hline \multirow[b]{2}{*}{ Date } & \multicolumn{2}{|c|}{ Local thunderstorms } & \multicolumn{2}{|r|}{ Sporadic E } \\
\hline & $\begin{array}{l}\text { Time of } \\
\text { occurrence } \\
\text { (EST) }\end{array}$ & Intensity & Time (EST) & $\begin{array}{l}\text { Upper frequency of oc- } \\
\text { currence of sporadic E } \\
\text { (above } 4,500 \mathrm{kc} / \mathrm{s})\end{array}$ \\
\hline $\begin{array}{l}\text { April } 4 \\
\text { June } 6 \\
\text { Sune } 27\end{array}$ & $\begin{array}{l}1200 \text { to } 1500 . \\
1200 \text { to } 2200 \\
1430 \text { to } 1530 \\
1500 \text { to } 1600 \\
1200 \text { to } 1500_{-}\end{array}$ & Moderate & 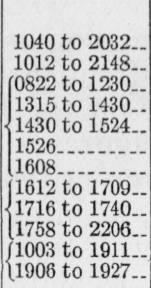 & $\begin{array}{l}\text { kc/s } \\
\text { No E reflections. } \\
\text { Do. } \\
8,400 \text {. } \\
\text { No E reflections. } \\
\text { No data; severe static. } \\
4,500 \text {. } \\
6,400 . \\
8,800 . \\
7,000 \text {. } \\
\text { No E reflections. } \\
\text { Do. } \\
\text { 5,000. }\end{array}$ \\
\hline
\end{tabular}

The data for nonlocal thunderstorms were taken from the weather maps and other material furnished by the Weather Bureau. The thunderstorms were given only for the 12 -hour periods 0800 to 2000 
and 2000 to $0800 \mathrm{EST}$ and no indication of the intensity was given; some of the storms being indicated by a single clap of thunder. On July 4 the weather was locally fair, but one thunderstorm was reported just inside the 100 -kilometer radius and another in the 100 to 200 kilometer zone. No precipitation was indicated so that it might be concluded that these were very minor storms. At about 1900 EST on the evening of July 4 sporadic $\mathrm{E}$ was found up to 10,800 $\mathrm{kc} / \mathrm{s}$, the highest so far recorded. This is shown in figure 5. Therefore close correlations in time between the occurrence of distant thunderstorms and sporadic $\mathrm{E}$ were not always possible. In the case of local thunderstorms, however, the time of occurrence was observed by us, and a fair estimate of the electrical intensity of the storm was also obtained. Therefore, if there is a correlation between the occurrence of thunderstorms and sporadic E, this correlation should be more positive for the case of local thunderstorms than for the thunderstorm data taken from the weather maps.

Table 2 shows the occurrence of sporadic E during the days on which no thunderstorms occurred within a radius of 300 kilometers of Washington. The above data fail to indicate a direct correlation between thunderstorms and sporadic E. Sporadic E is just about as prevalent on days when there are no thunderstorms within 300 kilometers as when there are severe local thunderstorms. Both phenomena are at a maximum during the summer months and this fact in itself suggests a correlation, but when the occurrences of thunderstorms and sporadic $\mathrm{E}$ are compared in more detail the correlation fails.

TABLE 2.-Sporadic E for days on which no thunderstorms occurred within 300kilometer radius during summer of 1934

\begin{tabular}{|c|c|}
\hline Date & $\begin{array}{l}\text { Upper frequency of oc- } \\
\text { currence of sporadic } \mathrm{E} \\
\text { (above } 4500 \mathrm{kc} / \mathrm{s} \text { ) }\end{array}$ \\
\hline $\begin{array}{l}\qquad 1934 \\
\text { April 18 } \\
\text { May } 2 \\
\text { May } 9 \\
\text { May } 16 \\
\text { June } 13 \\
\text { June } 20 \\
\text { July } 11 \\
\text { July } 18 \\
\text { August } 8 \\
\text { August } 22 \\
\text { August } 29\end{array}$ & $\begin{array}{l}\quad \mathrm{kc} / \mathrm{s} \\
\text { No E reflections. } \\
\text { Do. } \\
\text { Do. } \\
\text { Do. } \\
7,000 . \\
7,800 . \\
8,000 . \\
6,800 \text {. } \\
9,200 \text {. } \\
\text { No E reflections. } \\
\text { 7,500. }\end{array}$ \\
\hline
\end{tabular}

Another phenomenon believed to be a manifestation of the sporadic E layer occurred frequently during the early evening of the fall and sometimes winter on the frequency band 1,600 to $2,500 \mathrm{kc} / \mathrm{s}$. This is illustrated by figures 8 and 9 for October 6, 1933 and January 3, 1934. The E-layer critical frequency was observed to drop below $1,600 \mathrm{kc} / \mathrm{s}$ (fig. 8, a, b, c) before sunset. E-layer reflections accompanied by strong F-layer refractions sometimes remained at frequencies above $f_{E}$ as shown in figure 8. Later in the evening the $\mathrm{E}$ reflections became stronger and still later they weakened as in Figure 8 (f) and later disappeared. There usually was little question but that the second reflection was from the $\mathrm{F}$ layer rather than an $\mathrm{E}$ multiple. The second reflection was frequently stronger than the 
first $\mathrm{E}$, thus indicating that it was not a multiple of the first. The most prominent higher multiples were properly spaced to be multiples of the second reflection rather than the first. Also the F criticals sometimes appeared even while the E reflections were still present, figure $8(e, f)$, but no critical was found for the lower reflections.

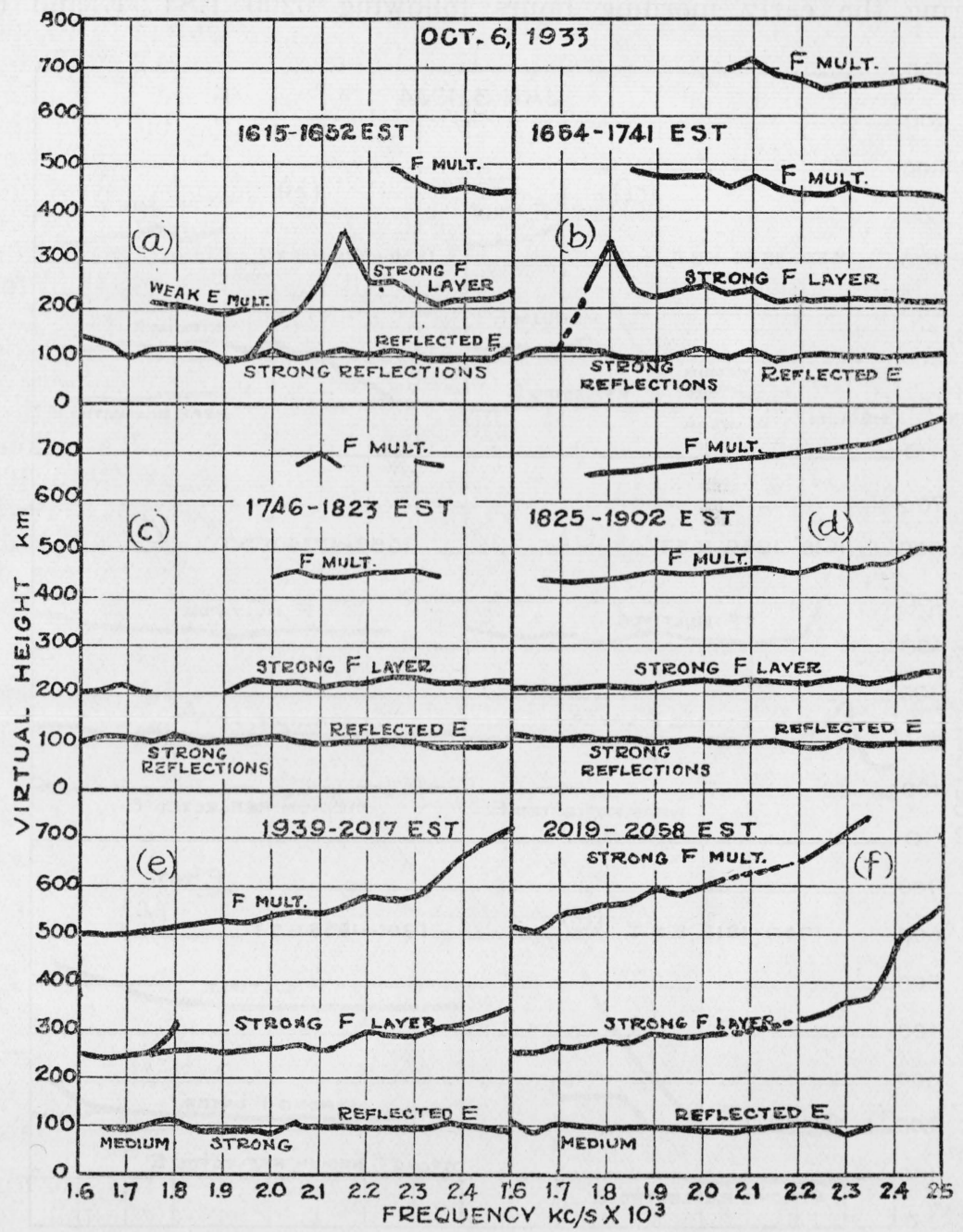

FIgURE 8.-Typical fall curve showing simultaneous appearance of $\mathrm{F}$ refractions and sporadic E-layer reflections after the normal E-layer critical had passed.

More frequently as $f_{\mathrm{E}}$ decreased during the early evening the $\mathrm{E}$ reflections became very weak or disappeared as shown in figure 8 ( $\mathrm{a}, \mathrm{b}, \mathrm{c})$. Later in the evening these $\mathrm{E}$ reflections became strong, figure 8 (c, d) while strong $\mathrm{F}$ layer refractions with multiples continued to come in, figure $8(\mathrm{~d}, \mathrm{e})$. Usually except during the summer 
the sporadic $\mathrm{E}$ disappeared from this frequency band later in the evening by a gradually weakening process and without showing a pronounced rise in virtual height such as indicates a critical frequency as shown in figure 8 (f).

Somewhat similar results have been observed in the broadcast band during the early morning hours following 0200 EST. E and F

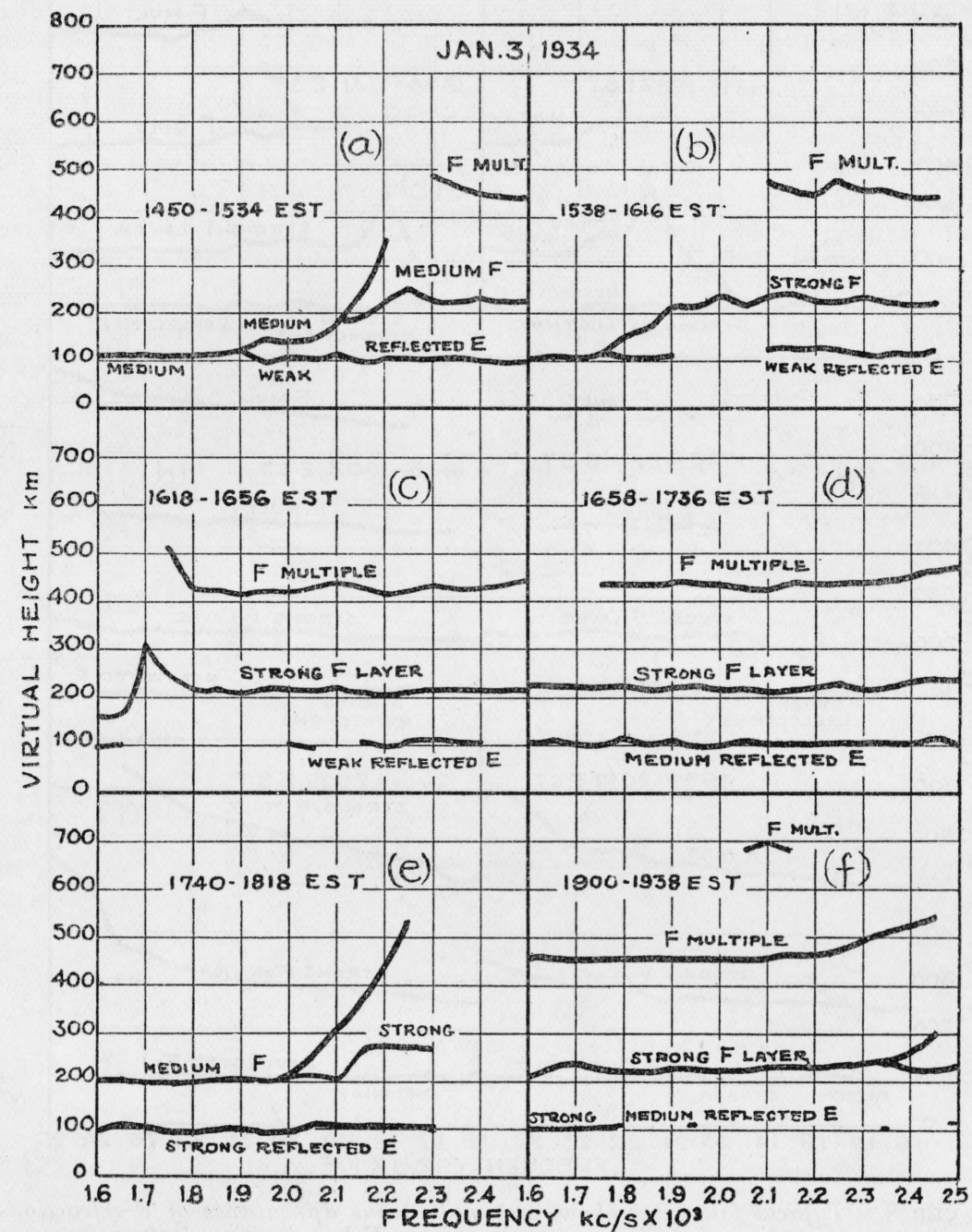

FIGURE 9.-Typical winter curve showing simultaneous appearance of $\mathrm{F}$ refractions and sporadic E-layer reflections after the normal E-layer critical had passed.

layers are frequently received simultaneously, no $\mathrm{E}$ critical frequencies were found and the disappearance of the E-layer reflections was marked by a gradual weakening rather than a critical and a sharp cut off. It is believed that during much of the time at night $\mathrm{E}$ reflections at broadcast frequencies are manifestations of the sporadic $\mathrm{E}$ 
and the $\mathrm{E}$ critical $f_{\mathrm{E}}$ if it exists is frequently at a frequency lower than $600 \mathrm{kc} / \mathrm{s}$. Figure 10 shows a typical night run of this kind.

\section{G AND HIGHER LAYERS}

The $\mathrm{F}_{2}$ layer is not very evident during the summer midday. One or two hours before sunset refractions from this layer attain moderate intensity and the critical frequencies can be followed during the summer. At about the time of sunset or a little later, reflections of medium intensity suddenly appeared from a virtual height as great or greater than the $\mathrm{F}_{2}$-layer virtual height and at frequencies higher than $\mathrm{F}_{2}$ at any other time. During the earlier observations it was believed that the $\mathrm{F}_{2}$-layer ionization increased rapidly to high values at these times. However, recent observations indicate that this phenomenon is produced by another higher layer, which is either found about this time or more likely uncovered by lower absorbing layers at the approach of sunset. We have tentatively called this the G layer. Figure 11 shows six sweeps taken in the succession indicated

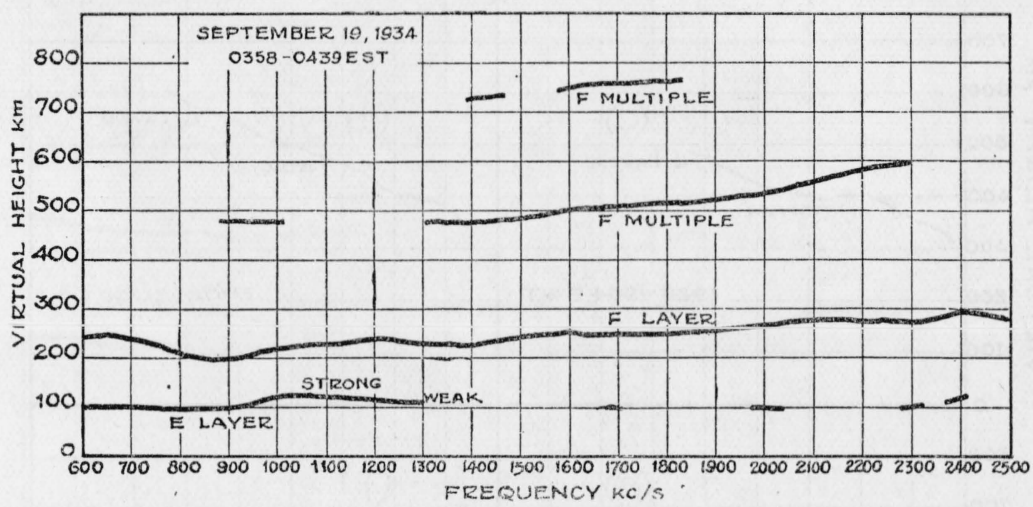

FIGURE 10. Typical curve of sweep through the broadcast range of frequencies during the night.

by the lettering, on the evening of August 1, 1934; a and b show the $\mathrm{F}_{2}$ critical frequency decreasing with advancing time; $b$ shows the formation of the G layer; c,d,e, and $f$ show only the G layer remaining. The G-layer reflections were of medium amplitude. The virtual height increased with frequency in a peculiar manner. No critical frequencies and no magnetic double refraction were observed. The reflections at higher frequencies gradually became weaker and were finally lost in the noise. The effect shown in figure 11 occurs on summer evenings.

An additional effect which has been found at other seasons during both day and night ${ }^{8}$ is shown in figure 12 for November $10,1933$. Complex reflections are returned from great virtual heights at frequencies above the $\mathrm{F}_{2}$ critical frequencies. The virtual height versus frequency graphs have the characteristic slope found for the $\mathrm{G}$ layer during the summer evening and these reflections were probably from the same layer. The reflections shown in figure 12 were ${ }^{8}$ Kirby, Berkner, and Stuart, BS J.Research 12, 15 (1934) RP632; also Proc.Inst.Radio Engrs. 22, 481
(1934). 


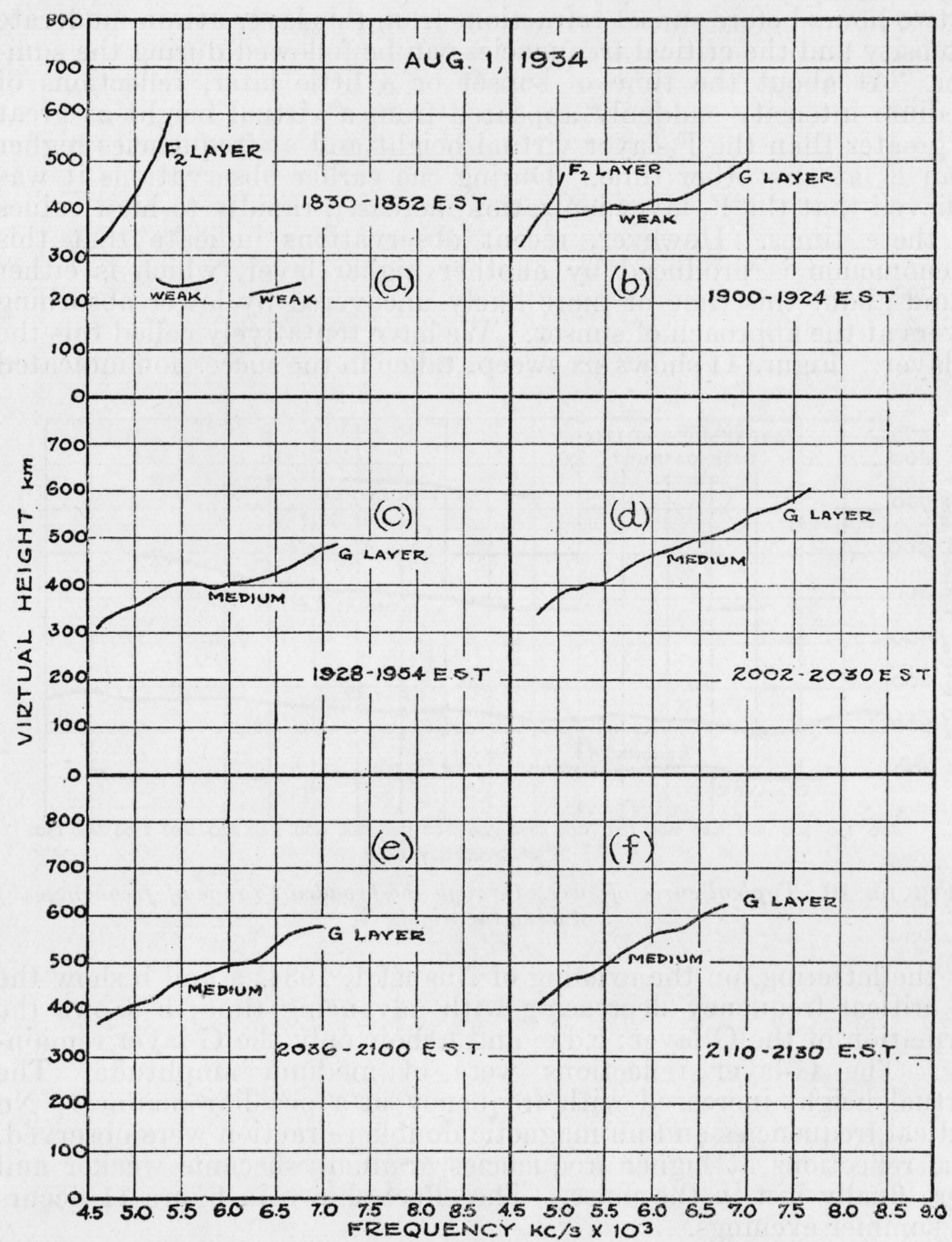

FigURe 11. Formation of the $\mathrm{G}$ layer during a summer evening. 


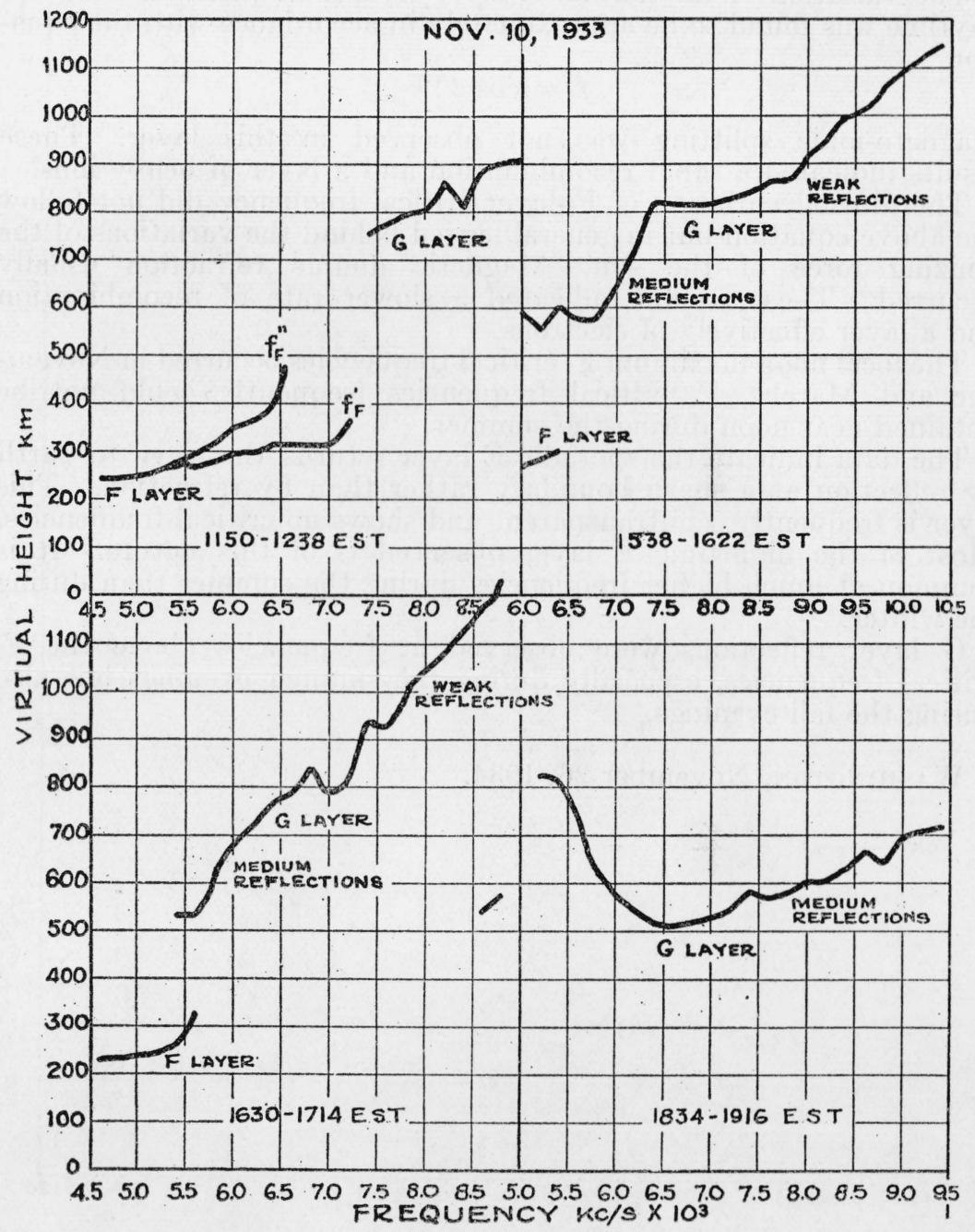

FIGURE 12. G-layer reflections for a winter day. 
usually weaker than those of figure 11 and were complex, so that even if they were present during the summer they would be more likely to be lost in the higher noise background.

\section{CONCLUSIONS}

The variation of the normal E-layer critical frequency during the daytime was found to be approximately in accordance with the equation

$$
f_{\mathrm{E}} \approx(\cos \psi)^{1 / 4}
$$

Magneto-ionic splitting was not observed in this layer. These results indicated a rapid recombination and a layer of heavy ions.

The diurnal variation of $\mathrm{F}_{2}$-layer critical frequency did not follow the above equation but in general lagged behind the variations of the ionizing force of the sun. Magnetic double refraction usually occurred. These results indicated a slower rate of recombination and a layer effectively of electrons.

The local noon maximum $\mathrm{F}_{2}$ critical frequencies occurred in November and March. $\mathrm{F}_{2}$ critical frequencies frequently could not be obtained near noon during the summer.

The data indicate the sporadic $\mathrm{E}$ layer returns the wave to earth by reflection at a sharp boundary rather than by refraction. This layer is frequently semitransparent and shows no critical frequencies. Most of the nighttime E layer observed is of this nature. It is common at much higher frequencies during the summer than during the winter.

$G$ layer reflections were observed at frequencies above the $F_{2}$ critical frequencies, especially during the summer evenings but also during the fall evenings.

Washington, November 26, 1934. 